\title{
A BONECA BARBIE NA CULTURA LÚDICA: BRINQUEDO, INFÂNCIA E SUBJETIVAÇÃO
}

\author{
Michelle Brugnera Cruz Cechin \\ mibrugnera@gmail.com \\ Thaise da Silva \\ thaiseds@ibest.com.br
}

\section{Resumo}

Envolta em um mundo de beleza, riqueza e aventura, a boneca Barbie está imersa em uma pedagogia cultural com o intuito de ensinar a supremacia de um tipo de corpo, raça e comportamento. $\mathrm{O}$ artigo tem como objetivo discutir as representações da boneca Barb ie na cultura lúdica e o modo que ela tem afetado a construção das identidades infantis, especialmente em relação ao gênero e à diversidade cultural. Analisa-se o que estudos específicos têm revelado sobre as representações culturais da boneca. Para tanto, foram tomados como referencial os Estudos Culturais, tendo como marco teórico a abordage m PósEstruturalista de análise, tratando a boneca como um artefato cultural. Destacam-se seus efeitos produzidos na mídia e na configuração discursiva da infância.

Palavras-chave: Infância. Subjetivação. Diversidade. Gênero. Jogos e Brinquedos.

\section{Vamos brincar com a Barbie?}

A boneca manequim mais famosa do mundo, Barbie, envolta em um mundo cor -derosa, que evoca magia e fantasia, pode parecer apenas um simples e inoc ente brinquedo para entreter e divertir crianças. No entanto, ao se revisitar sua história, emergência e permanência no mercado de brinquedos, vê-se que sua produção está imersa em intenções pedagógicas, com o intuito de ensinar a supremacia de um tipo de corpo, raça e comportamento (BROUGÈRE, 2004; STEINBERG, 2001; DEBOUZY, 1996; ROVERI, 2008). Em seus mais de 50 anos de existência, sua fabricante, a Mattel, tem criado inúmeros artefatos midiáticos, como utensílios, roupas, acessórios e cenários, com o intuito de aumentar as vendas da boneca, fomentando a cultura do consumo (BROUGÈRE, 2004; STEINBERG, 2001; DEBOUZY, 1996; ROVERI, 2008).

Desde a antiguidade, as bonecas fazem parte das diferentes culturas, refletindo as relações culturais, políticas e econômicas instituídas nas sociedades e remetendo a diferentes formas de organização da vida das crianças. Historicamente as bonecas fazem parte das brincadeiras infantis e representam o conceito que a sociedade tem da infância (BROUGÈRE, 
2001; 2004; BUJES, 2004; SOUZA, 2009). São portadoras de significados e valores culturais que revelam discursos, concepções e representações de determinada sociedade e cultura. Segundo Brougère (2004), o brinquedo participa da construção da infância através de complexos significados e práticas produzidas não apenas por seus criadores e difusores como também por aqueles que o utilizam. É possível entender o lugar da criança na sociedade por meio dos usos e significados atribuídos aos brinquedos. Optou-se pela boneca Barbie como objeto de investigação por ter uma forte presença nos lares e nas escolas, bem como por s e mostrar uma importante portadora de significados e valores culturais.

Cada vez mais se desenvolve nos meios educacionais um discurso relativo ao valor da brincadeira, ampliando o valor do brinquedo na educação escolar (BROUGÈRE, 2001; BUJES, 2002). Muito se estuda a importância das brincadeiras para o desenvolvimento infantil; porém, pouco se analisa os significados culturais, históricos e peculiares dos brinquedos, refletindo-se sobre eles (SANTOMÉ, 2009; BUJES, 2002). A falta de reconhecimento das formas culturais da infância, como o veículo de representação e a ausência de problematizações desses artefatos culturais no contexto das salas de aulas, relega a cultura infantil a uma posição subalterna em relação a outras disciplinas acadêmicas (GIROUX, 2009; SANTOMÉ, 2009).

O presente estudo aborda as bonecas a partir do momento em que elas começaram a ser destinadas às crianças, junto à emergência das primeiras noções de infância na era moderna. A fundamentação dessa análise está nos estudos de Philippe Ariès (2006), que trata das diferentes visões de infância ocorridas ao longo da história e de como as bonecas participaram da vida das crianças. Para a análise das representações culturais da boneca Barbie, tomou-se como referencial teórico estudos anteriores específicos sobre o tema (DEBOUZY, 1996; STEINBERG, 2001; BROUGÈRE, 2004; ROVERI, 2008), que analisam as narrativas da publicidade por trás da Barbie.

\section{1. "Barbie resiliência": a nova ordem dos brinquedos plásticos}

Estima-se que, desde a sua criação, um bilhão de bonecas Barbies foram vendidas em mais de 150 países (LORD, 2004). Com o status de boneca mais vendida do mundo, seu sucesso é sempre vinculado à beleza, à juventude e ao consumo. Devido às diversas adaptações visuais e à representação de diferentes etnias, a boneca norte -americana acompanhou as mudanças de tendência em moda, beleza e comportamento e construiu uma memória da cultura ocidental (LORD, 2004; ROVERI, 2008). 
Para a Física, a resiliência se refere à capacidade dos materiais plásticos de voltar à sua forma quando são forçados a se deformar. A Psicologia se valeu desse conceito para designar as competências de adaptabilidade, superação de desafios com alegria e otimismo; enfrentar, vencer e sair fortalecido de situações adversas (MELILLO, 2006). A resiliência da Barbie está em sua adaptabilidade aos novos tempos, seu sucesso só foi possível pela sua "plasticidade" visual. Sua grande capacidade de mudança permitiu-lhe a hegemonia no mercado de bonecas. Para Barthes (1982), o plástico não é uma mera substância e sim a própria id eia de transformação infinita, o vestígio de um movimento que se transforma tanto em um brinquedo quanto em uma joia:

[...] uma matéria artificial, mais fecunda do que todas as jazidas do mundo, vai substituí la [a natureza] e comandar a própria invenção das formas". O plástico é totalmente absorvido pela sua utilização: em última instância, inventar -se-ão objetos pelo simples prazer de os utilizar. Aboliu-se a hierarquia das substâncias, uma só substituiu todas as outras: o mundo inteiro pode ser plastificado, e mesmo a própria vida, visto que, ao que parece, já se começaram a fabricar aortas de plástico (BARTHES, 1982, p .113, gri fo do original).

A indústria se apropriou de brinquedos como bolas, bonecas e carrinhos, que anteriormente eram acessíveis a inúmeras crianças. Foram artificializados e apri sionados nas malhas do poder econômico. O plástico tornou isso possível, pois substituiu uma variedade de materiais usados na confecção manual de brinquedos, oferecendo a eles uma vida mais longeva e resistente (ROVERI, 2008).

Segundo Ariès (2006), as bonecas tiveram sua origem permeada pelas imagens e estatuetas com significação religiosa, que estiveram presentes na vida humana desde a Pré História. As crianças não tinham o direito de se aproximar dessas estátuas ou manipulá-las, pois se acreditava que possuíam poderes mágicos e eram tid as como objetos sagrados.

As bonecas somente passaram a ser objeto destinado à educação e ao divertimento das crianças junto à "emergência do sentimento de infância" que, segundo Ariès (2006), ocorreu no século XVII, tornando possível um discurso sobre a criança. De acordo com o autor, anteriormente não se concebia a diferença entre adultos e crianças; portanto, não havia a noção de passagem das idades da vida, as crianças ingressavam na vida adulta assim que eram consideradas capazes de dispensar a ajuda das mães ou das amas, aproximadamente aos sete anos de idade.

Foram nos séculos XVII e XVIII que fatores históricos, políticos e educacionais determinaram o surgimento desse n ovo conceito de infância. Com a Revolução Industrial e o modo de produção fabril, a família e a escola afastaram a c riança da sociedade dos adultos. 
Houve o advento das famílias, das casas divididas em cômodos, o início da vida privada. Essa transformação social tornou possível um discurso sobre a criança, passou -se a estudar e pensar a infância, caracterizando-a como inocente, ne cessitando de cuidado e proteção.

Esse novo regime discursivo impulsionou a criação de diferentes artefatos culturais destinados ao controle, "governamento" (FOUCAULT, 1970) e produção dos infantis. A criança passou a ser alvo de estudos nas mais variad as áreas de conhecimento. No bojo das discussões de especialistas, surgiram as tentativas de compreender o papel do jogo e do brinquedo na formação do sujeito. O brinquedo e as bonecas saíram da esfera do simbolismo religioso que tiveram no passado para ha bitar o mundo exclusivo da criança .

No século XX, com o avanço da indústria, os fabricantes passaram a produzir bonecas com distintos materiais e introduziram dispositivos mecânicos e eletrônicos nesses objetos. Nesse momento, os brinquedos receberam uma conotação de produção bastante complexa, através da aplicação de diferentes técnicas e conhecimentos, como a análise do mercado, as expectativas do consumidor, a criatividade, o design das embalagens e acessórios e os testes em modelos fabricados (BROUGÈRE, 2001).

Segundo Steinberg (1997), as crianças foram descobertas como consumidoras em potencial a partir da década de 50 do século XX, com o surgimento de novas tecnologias produzidas após a Segunda Guerra Mundial. Desde então, uma série de produtos têm sido direcionados para elas nos mais variados segmentos.

Barbie foi criada neste contexto pós-guerra, uma época que possibilitou o aumento do consumismo capitalista, e o imaginário burguês foi levado às camadas populares através de diferentes ícones. É a principal representante da modalidade de bonecas manequim (BROUGÉRE, 2004; MITCHELL, REID-WALSH, 2007; DEBOUZY, 1996), que incentivam outro tipo de brincadeira. O objetivo não é cuidar e alimentar a criança-boneca, mas ser a boneca adulta. Inicialmente, eram feitas de porcelana, corpo de tecido e utilizavam roupas com modelagem da moda. Posteriormente, foram elaboradas em papel e acompanhavam os encartes das revistas de moda da época.

A Barbie tem descendência alemã da boneca Lilli, que serviu de modelo para sua criação. Lilli fora criada em 1950, inspirada na personagem de quadrinhos do jornal Bild Zeitung (LORD, 2004; BROUGÈRE, 2004; GERBER, 2009; STONE, 2010). Era voltada para o público adulto, pois sua representação nas histórias tinha uma conotação porno gráfica. A personagem costumava perseguir homens ricos em busca de dinheiro e sucesso. Com a produção da personagem em boneca, Lilli tornou-se um objeto icônico para os homens 
adultos, vendida em bares e tabacarias. Lilli não era direcionada para crianças ; contudo, as crianças se apossaram dela.

Ruth Handler e Elliot Handler foram os fundadores da empresa de brinquedos Mattel, que fabrica a Barbie. Ruth Handler, ao observar sua filha Bárbara brincando, viu que ela interessava-se mais por suas bonecas de papel, pois estas tinham o corpo de uma mulher adulta e possuíam uma grande variedade de roupas que podiam ser trocadas (LORD, 2004; BROUGÈRE, 2004). Em 1956, o casal passava as férias com a família na Suíça quando Ruth, fazendo compras com sua filha, viu um a boneca que não conhecia. A menina quis comprá -la para enfeitar seu quarto, e a mãe levou duas bonecas para a filha e uma para entregar aos executivos da Mattel, pois havia vislumbrado a possibilidade de fabricar uma boneca com corpo adulto, como há anos desejava criar. Desde sua precursora, o tema da moda e a oferta de diferentes vestimentas eram um dos seus principais atrativos:

As bonecas Lilli tinham uma aparência alongada e eram vestidas com lindos trajes. Um deles era uma roupa de esqui; outro era u m traje típico de uma região da Europa. Ruth e Bárbara nunca haviam visto bonecas como aquelas, exibidas no interior da loja, e Ruth sugeriu que comprassem uma para enfeitar o quarto de Barbara, já que ela havia passado da idade de brincar com bonecas. Barbara ficou encantada, mas, diante das bonecas com trajes tão diferentes, achou difícil escolher uma só. Ruth tentou comprar as roupas separadamente, mas foi informada de que elas não eram vendidas desta maneira. Se um cliente queria um traje diferente, tin ha que comprar a boneca junto. (GERBER, 2009, p. 19).

Inspirada no interesse de sua filha, Ruth deu inicio ao processo de criação das formas do corpo e do rosto da boneca Barbie, que durou três anos. Serviram como inspiração para o visual da boneca atrizes famosas da época, como Grace Kelly, Marilyn Monroe, Bridget Bardot. A produção da época exigia maquiagem forte, sombras prateadas e muito delineador, unhas e batom vermelhos, corpo curvilíneo e pele pálida, tal qual as atrizes do período (LORD, 2004; ROGERS, 1999).

Ela foi lançada oficialmente na Feira Anual de Brinquedos de Nova Iorque, em 9 de março de 1959. Com trinta centímetros de altura, dois centímetros de cintura, braços rígidos e articulados, cabelos de náilon, vestindo maiô de listras pretas e b rancas, salto alto e maquiagem, era uma top model (figura 1). A Mattel chamou Barbie de "Modelo de Moda Adolescente" na tentativa de amenizar seu visual sensual e acentuar a id eia de que as meninas desejavam se parecer e se vestir como as modelos (GERBER, 1999). Para Steinberg (2004, p.325): 
Ela era uma modelo adolescente. Garotas deixavam de embalar bonecas bebê para exigir o mais recente da alta costura à la Mattel. A Barbie era sexy, apesar da maioria das suas proprietárias sequer estar preocupada com sua sexualidade - elas apenas amavam as suas Barbies.

Neste mesmo mês, Barbie estreou na televisão, não como uma boneca, mas como uma adolescente que nadava, dançava, ia a festas e trocava muitas vezes de roupa. Em seu primeiro comercial, Barbie aparece sob luzes intensas diante das câmeras com o intuito de tornar sua imagem glamorosa, ao embalo da canção que dizia: "Um dia serei como você, até lá sei o que vou fazer [...] Barbie, linda Barbie, vou fingir que sou você” (GERBER, 1999).

Ruth e Eliot venderam 34.000 bonecas desse primeiro exemplar (LORD, 2004). A boneca fez grande sucesso entre as crianças; porém, as famílias americanas conservadoras não aprovaram a boneca por sua dimensão sexy. Sua maior inovação foi a possibilidade de as garotas poderem possuir apenas uma boneca, já que estas podiam ter diversas "roupas" (SOUZA, 2009; STEINBERG, 2004). Em uma entrevista, Ruth afirmou que a Barbie:

É um produto muito educativo: as crianças aprendem combinações de cores, desenhos de moda, cuidados pessoais, penteados, boas maneiras, e relacionamentos interpessoais - elas interagem por meio de situações sociais. (GERBER, 2009, p. 158)

Conforme Brougère (2004), a inovação da Barbie não estava no objeto em si, mas na concepção de um brinquedo novo, que se inscreveu mais precisamente em uma nova ordem lúdica. A partir do objeto boneca, foi construída uma personalidade, tramada progressivamente através da narração que se fazia sobre ela. "O fabricante não vendia mais um objeto, e sim uma personalidade, uma história, um sonho" (BROUGÈRE, 2004, p.100).

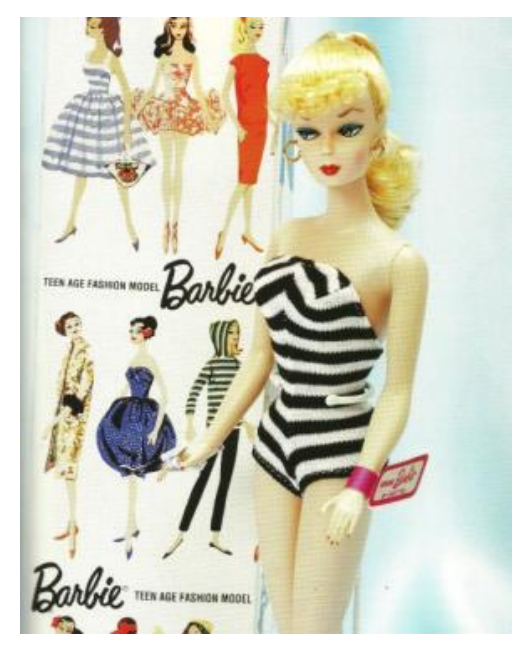


Figura 1: Primeira versão da Barbie (STONE, 2010)

A união do brinquedo com a televisão ganh ou força a partir de 1960. As grandes corporações uniram mídia e brinquedo, criando inúmeros artefatos voltados para o laze $\mathrm{r}$ das crianças. Essas práticas produziram diferentes discursos que visavam formar o consumidor. Diante disso, os brinquedos industrializados se tornaram uma potencial mercadoria (DORNELLES, 2001, 2008; BROUGÈRE, 2004). Com o intuito de vender mais, as grandes indústrias passaram a unir mídia e brinquedo, fabricando múltiplos bonecos, jogos e fantasias relacionados a filmes ou desenhos da televisão. Brougère (2001, p. 18) argumenta: “As pressões da propaganda na televisão, a publicidade, os desenhos animados, que dão origem aos personagens de brinquedos, levam a aumentar, ainda mais, a dimensão expressiva e simbólica do brinquedo, pela qual ele vai se diferenciar de todos os outros ".

Nessa perspectiva, pode-se dizer que a boneca Barbie é um objeto com identidade cultural, pois seu sucesso pode ser atribuído também às narrativas tramadas sobre ela em diferentes mídias, que construíram e renovaram suas diversas identidades, adequando-as à cultura de cada época.

\section{2. "Barbie professora": as pedagogias de gênero da boneca}

Encaminhar as meninas ao mundo imaginário da boneca é a principal publicidade da Barbie (STEINBERG, 2001; BROUGÈRE, 2004; ROVERI, 2008; SOUZA, 2009). Imersa em um mundo cor-de-rosa, repleta de acessórios da moda e objetos de prestígio, a menina consumidora é convencida de tê-los em sua coleção. Sua marca cor-de-rosa ensina e produz certas formas de pensar, agir, estar e se relacionar com o mundo. No site "Viva o Rosa" (MATTEL, 2009), comemorativo aos seus 50 anos, um texto direcionado aos pais diz:

Rosa é a maneira alegre e espontânea de viver, em que cada menina celebra seus sonhos e com ela a possibilidade de ser o que quiser! [...] Viva o rosa reforça a ideia de que cada menina pode transferir para a vida real elementos delicados e femininos que fazem parte do mundo da boneca. Por isso, convidamos você a participar também deste universo onde o rosa é sinônimo de alegria!

A Barbie ensina às crianças que devem se dedicar à busca da felicidade através da aquisição de bens materiais. Sua pedagogia de consumo dá diversas lições sobre adquirir bens que deem status de riqueza, acompanhar as tendências da moda e ter um estilo de vida "divertido". Com esses objetivos, a roupa se torna central, pois faz com que você seja alguém 
especial e "popular", um conceito fundamental da vida social na década de 1950 (DEBOUZY, 1996).

Vestida por estilistas famosos como Calvin Klein e por designers de sa patos como Christian Louboutin, o "guarda-roupa" versátil da Barbie opera no permanente jogo de novidade e renovação apresentado pela indústria da moda. Suas diferentes vestimentas fomentam a necessidade de consumo. O episódio Lisa e a Boneca Falante, da quinta temporada da série televisiva Os Simpsons, satiriza as manobras que são forjadas através das roupas da boneca para manter sua hegemonia status de referência para as meninas (SOUZA, 2009).

Em seu mais recente filme, lançado em setembro de 2011, Barbie é apresentada como uma garota órfã e pobre, sorteada para estudar na Escola de Princesas. O site do filme descreve a escola como "um lugar incrível, onde as alunas aprendem dança, etiqueta e outras habilidades indispensáveis a uma futura princesa" (MATTEL, 2011 a). Seguindo seu propósito pedagógico, o site apresenta seus ensinamentos aos pais:

\begin{abstract}
Neste site sua filha vai aprender junto com a Barbie e sua turma como se comportar como uma princesa de verda de. Além de poder acompanhar a história de sucesso e amizade da Blair, ela também irá se divertir em cada uma das 15 aulas de princesas. São 15 lições diferentes abordando os temas: graça, charme, postura e etiqueta. Convide sua filha para conhecer a Escol a de Princesas e essa emocionante história! Complete todas as lições para se tornar uma princesa como Barbie.
\end{abstract}

As lições da boneca incluem postura e equilíbrio, montagem de j oias, como se vestir para ocasiões e customização do uniforme. As lições de moda e comportamento são muito frequentes em seus filmes. O grande objetivo é se tornar uma "ve rdadeira princesa". No filme Barbie em A Princesa e a Plebeia, o clipe da música "Como ser uma Princesa" ensina o comportamento adequado a uma verdadeira princesa:

Uma princesa sabe usar uma colher. Tem mil sapatos para escolher o que quiser. Tem conduta exemplar, é discreta ao jantar e demonstra interesse em ouvir. Pés delicados ao dançar. O protocolo respeitar. Goste ou não a solução é dizer sim. Sua postura, por fav or! Mais elegante que uma flor. Saber curvar e acenar assim [...] O seu porte é perfeito, sem manias ou trejeitos! (MATTEL ENTERTAINMENT, MAINFRAME ENTERTRAINMENT, 2004).

A coleção de bonecas Barbie que ilustra a essência da troca de roupas nas brincadeir as é a linha Fashion Fever, criada em 2004, uma série de mais de 20 modelos de bonecas com estilos diferentes de se vestir renovadas semestralmente, descritas como "superglamorosas, 
elas não seguem a moda. Elas começam a moda! É assim que são as bonecas Fashion Fever, muito estilo e atitude" (MATTEL, 2011c). Essa coleção foi reformulada em 2009, passando a se chamar Fashionistas Mudando o Visual, através de oito modelos de roupas, aprende -se a diferença entre os estilos glam, sweetie, cutie, sporty, artsy, sassy e hotti. Se em sua origem Barbie foi criada com o intuito de a menina possuir apenas uma boneca e muitas roupas, atualmente a Mattel investe para que a menina tenh a muitas bonecas, muitas roupas e um arsenal de acessórios e cenários.

No site específico dessa coleção, há diferentes “jogos” em que a menina pode elaborar diversas combinações de roupas, montar um estúdio fotográfi co e fazer um "teste" para descobrir com qual fashionista ela se parece. O grande objetivo desses artefatos midiáticos é fascinar as meninas através do jogo de combinações e novidades visuais, seduzindo -as a adquirir novos acessórios, roupas e maquiagens.

Ao representar diferentes profissões, artistas de cinema, personagens de filmes e seriados, Barbie evoca o prazer da aparência, um sentimento narcisista de se transformar através do "visual". Seu slogam "Seja tudo o que você quiser: Barbie girl!" ensina que as meninas podem ser "livres" para ser o que quiserem através da moda e dos cuidados com a aparência (ROGERS, 1999; ROVERI, 2008).

Uma das estratégias da Mattel é elaborar diferentes linhas da boneca Barbie, separadas em temas que englobam "fantasia", "mundo da moda", "profissões" ou "esportes". Se uma menina compra a Barbie Mariposa (figura 2), esta terá asas, cabelos coloridos, acessórios e cenários próprios e certamente não conseguirá vestir a boneca com as roupas e os acessórios da coleção voltada para moda, como a linha Fashionista. A fabricante criou diversas estratégias para direcionar as brincadeiras infantis, produzindo formas de operar sobre a criação das crianças, governando a ludicidade. As meninas são incentivadas a colecionar as bonecas e suas diferentes linhas, e não mais apenas roupas e acessórios. 

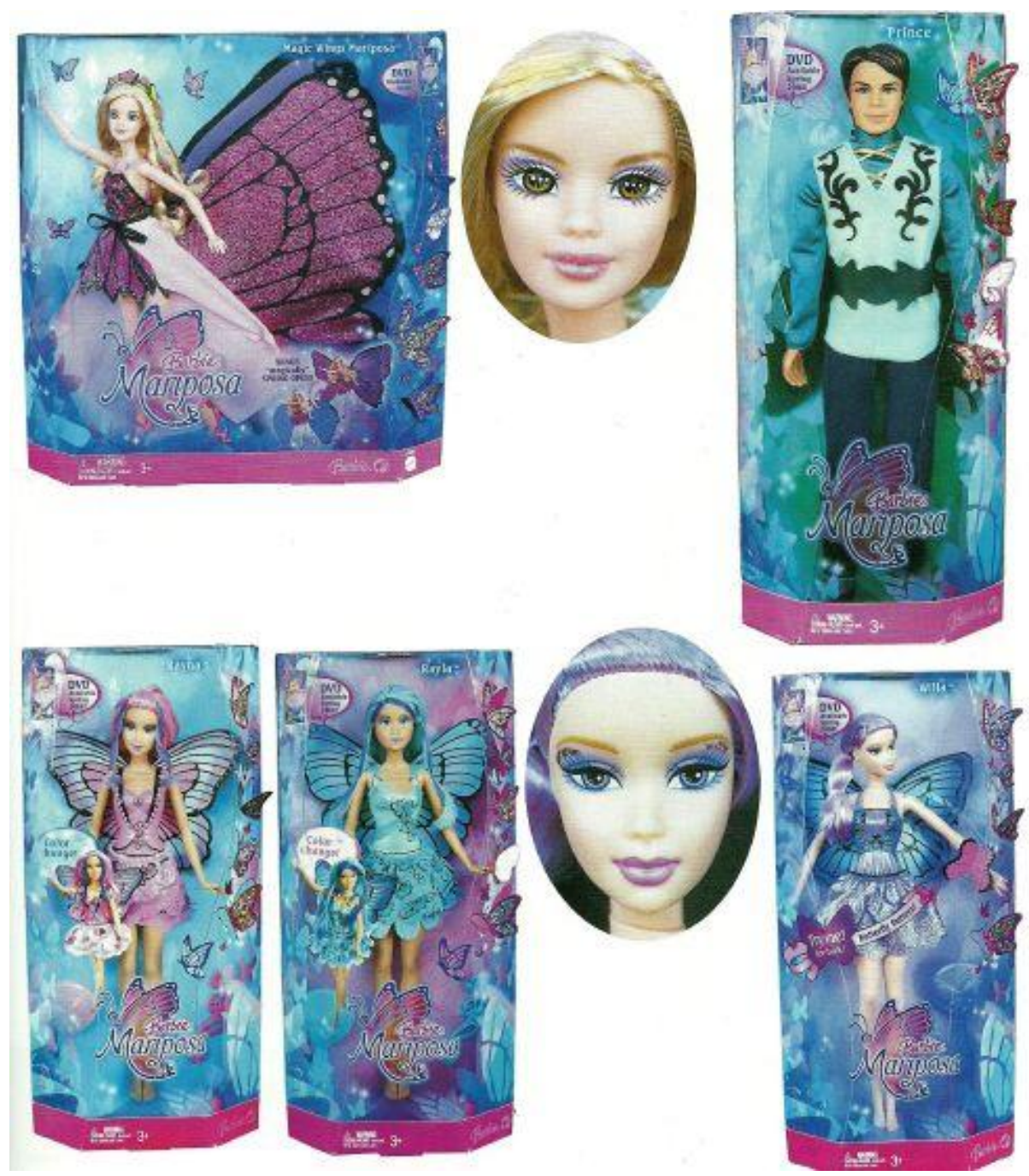

Figura 2: Coleção Barbie Mariposa (AUGUSTYNIAK, 2009)

Durante seus 52 anos de existência, Barbie ganhou a companhia de inúmeros amigos e amigas. Primeiro surgiu Ken, seu namorado, e em seguida seus amigos Midge e Allan; Skipper, a irmã mais nova de Barbie, e os gêmeos Tutti e Todd, também seus irmãos. Todas as amigas de Barbie podiam vestir suas roupas, exceto Francie, prima da boneca, que foi apresentada um pouco mais velha, baixa e curvilínea, o que exigia a criação de uma linha complementar de roupas exclusivas para ela.

Ken foi lançado em 1961, após 2 anos do lanç amento da Barbie na Feira de Brinquedos de Nova Iorque, em 1959, sendo relegado à acessório (BROUGÈRE, 2004) . Assim como "sua namorada", teve muitas versões acompanhando as mudanças da boneca e sua educação para o consumo e comportamento jovem. Um bom exem plo da personalidade de Ken pode ser localizado no terceiro filme da saga Toy Story, produzido pela Disney-Pixar em 
2010. Apesar de afirmar veementemente que "não é um brinquedo de menina", Ken possui muitas coisas, entre elas a "casa dos sonhos" e um vas to figurino, mostrando-se vaidoso e fútil através de suas falas: "ser o Ken é ter uma vida divertida!", "O Ken tem bons genes, que ficam lindos dentro de um jeans".

Esse boneco está presente nas brincadeiras tanto de meninas como de menin os, representando uma das múltiplas masculinidades que são forjadas na cultura atual através de diferentes artefatos. Para Brougère (2004, p.114):

\footnotetext{
Ken deixa os meninos confusos devido à sua indeterminação fundamental, uma representação masculina e acessória de uma brincade ira considerada feminina. É isso o que põe a categorização em perigo e é melhor dizer que ele é simplesmente "nulo", o que evita ter de revelar mais, mesmo que na intimidade da família, e com o pretexto das irmãs e primas, os meninos b rinquem com a Barbie.
}

Ken é um boneco controverso, pois algumas das suas versões causaram polêmica, como o Ken Brincos Mágicos, que fazia parte da coleção Barbie Brincos Mágicos, junto a seis bonecas. Ele foi o primeiro boneco a ser representado com brinco, cabelos pintados com "mechas" e estava vestido com uma camiseta e colete roxos. Muitos consumidores interpretaram o visual do boneco como a representação estereotipada de um homem homossexual, causando grande venda do boneco; porém, muitas críticas à Mattel, que o recolheu das lojas (LORD, 2004; AUGUSTYNIAK, 2010).

\footnotetext{
O boneco se tornava um ícone gay com o surgimento do Earring Magic Ken, em 1993. O brinquedo era uma resposta aos pedidos das crianças por um Ken mais moderno, mas a camisa rocha e colada, o brinco de brilhante e os sapatos pretos de amarrar continham mais que um apelo centrado na demanda infantil. Para a comunidade gay ainda discriminada e relativamente escondida, havia a afirmação de que o boneco Ken podia ser tanto heterossexual como homossexual. (GERBER, 200 9, p. 251)
}

A palavra "boneca" é empregada em brinquedos feitos para meninas. No lugar da palavra "boneco", os fabricantes usam o termo figuras de ação, que define os personagens como velozes, maldosos, heróis e viris vendidos aos meninos (BROUGÈRE, 2004; ROVERI, 2008). O termo foi primeiramente cunhado pela fabricante Hasbro em 1964, para divulgar os seus bonecos GI Joe, voltados para os meninos. O GI Joe era um boneco militar que vestia uniformes diferentes do exército americano. Em um movimento que criaria popularidade global para este tipo de brinquedo, a Hasbro também licenciou o produto para empresas em outros mercados, com os nomes de Action Man e Falcon no Brasil (BROUGÈRE, 2004; ROVERI, 2008). 
Figuras militares foram encontradas em antigos túmulos egípcios e apareceram em muitas culturas e eras. Posteriormente, tomaram forma de soldadinhos de chumbo, que foram produzidos na Alemanha em 1730. Soldados em miniatura também foram usados nos séculos XVII, XVIII E XIX por estrategistas militares para planejar táticas de batalha usando os números para mostrar a localização dos soldados rea is. Com a corrida espacial e o surgimento de diferentes artefatos culturais que representavam a ida do homem ao espaço, os brinquedos espaciais ficaram em destaque (BROUGÈRE, 2004). A partir do grande sucesso do filme Guerra nas Estrelas, foram produzidos bonecos dos personagens dos filmes em um tamanho menor ao das figuras de ação. O grande sucesso desses brinquedos criou um novo padrão para os bonecos em tamanho menor, relacionados aos filmes ou a programas de televisão. Desde então, foram criados muitos outros bonecos como o mais recente Max Steel (BROUGÈRE, 2004).

Max Steel é um brinquedo que representa um herói fictício que tem um incrível poder e trabalha para uma organização chamada $\mathrm{N}$-Tek, que desenvolve novas tecnologias. $\mathrm{O}$ boneco foi lançado após a exibição de uma série de animação em computação gráfica criada pela grande corporação de brinquedos Mattel. A Mattel lança, além do boneco, diversos brinquedos sobre o filme, que são exibidos nos curtas de Max, chamados de "Turbo Missions". A proposta da brincadeira é destruir, atirar lanças e projéteis, emitir sons aterrorizantes, detonar vilões, "ser forte na medida certa e deixar o mundo mais seguro", como anuncia a fabricante do boneco (MATTEL, 2011b):

\begin{abstract}
Max Steel é o agente top da N-TEK, que usa o poder Turbo, equipamento de alta tecnologia, e gosta de aventura para derrotar os vilões que ameaçam o mundo. A N TEK desenvolveu um novo biolink para ajudar Max a aproveitar seus níveis extremos de energia e dar poder para que ele ative o 'Modo Turbo'! Ele está 10 vezes mais forte e mais rápido do que qualquer humano e pode 'turbificar' suas armas e equipamentos para lutar contra vilões. Quando os vilões monstruosos causam o caos, só existe um cara para detê-los: Max Steel.
\end{abstract}

Connell (2005) descreve um conceito de masculinidade que prevalece na cultura ocidental: a masculinidade hegemônica, inclinada aos esportes, à competição, às ciências exatas, à racionalidade e à identidade heterossexual. As demais representações da masculinidade, como sensível, artística, homossexual ou bissexual, são chamadas de masculinidades subalternas por estarem em patamares inferiores de poder em relação às formas hegemônicas de masculinidade, sendo alvo de exclusão, violência e ridicularização. Os bonecos contemporâneos parecem representar bem tal distinção, já que o Max Steel representa os ideais da masculinidade hegemôni ca, enquanto Ken é um mero acessório. 
As estratégias de marketing dividem os brinquedos próprios para os meninos dos brinquedos voltados para as meninas, além das diferenças etárias, e pretendem ensinar as crianças a enxergar com naturalidade essa separação. Meninas e meninos são enquadrados em distintos segmentos do mercado, e a fabricação e a exposição dos brinquedos é realizada de modo a fixar uma identidade de gênero.

Os brinquedos da contemporaneidade vêm de fábrica imbuídos de normas que definem o que é permitido e o que não é permitido para cada gênero, há um abismo que separa os "brinquedos de guerra" destinados aos garotos, dos outros "brinquedos sensíveis" exclusivos das meninas (ROVERI, 2008; ZEGAI, 2007). A lógica que preside o mundo dos brinquedos dos meninos é diferente dos brinquedos produzidos para as meninas. As cores escolhidas pela publicidade para estampar as embalagens geralmente são mais escuras, os rostos com traços agressivos demonstram poder e seus membros são articulados para realizar inúmeros movimentos que simulam coragem e ousadia.

\section{3. "Barbie diversidade": o multiculturalismo por trás da boneca}

Enquanto as diferenças, a pluralidade cultural e a inclusão social são temáticas que se tornaram centrais no panorama educativo nos últimos anos, a fabrica nte da boneca Barbie percebeu que o discurso da diversidade tinha grande potencial de marketing em meados da década de 1960. Para a Mattel, diversidade consiste em tons de pele, países, línguas e hábitos alimentares diferentes dos da Barbie loura e branca. A pluralidade cultural foi relegada às amigas da Barbie, pois nada poderia retirar a su premacia da branca da boneca (ROVERI, 2008).

Lord (2004) afirma que o brinquedo é parte da indústria de entretenimento e que por isso também segue tendências. A partir da década de 1970, a indústria cinematográfica começa a produzir mais filmes com persona gens negros e a indústria de brinquedos investe na representação de afro-americanos nas bonecas, pois percebe o sucesso do merchandising multicultural. Contudo, passados mais de 50 anos da sua criação, Barbie continua preponderantemente magra, branca, com cabelos loiros, compridos e lisos. As marcas inscritas na representação corporal da Barbie mostram os ideais de beleza dos séculos XX e XXI, ensinando sobre o corpo ideal (STEINBERG, 2001; ROVERI, 2008; SOUZA, 2009). Barbie apresenta uma significação corporal feminina construída sob os moldes higienistas e eurocêntricos, educando para um tipo de beleza considerada hegemônica.

Steinberg (2001) diz que a Barbie loira é o padrão a partir da qual as outras surgem. Apenas nas amigas da Barbie e em suas edições p ara colecionadores é que encontramos uma 
maior diversidade fenotípica. A primeira amiga negra da Barbie foi Christie, criada em 1968. Ao longo dos anos, muitas outras amigas negras foram produzidas; contudo, elas apresentam as mesmas características da Barbie branca. A primeira Barbie negra foi lançada apenas em 1980, inscrita nos mesmos padrões norte-americanos de beleza e comportamentos juvenis legitimados em nossa cultura.

Na década de 1960, o movimento afro -americano e outros segmentos das minorias da sociedade americana passaram a questionar as imagens negativas das pessoas negras apresentadas por diferentes artefato s culturais. Diversas corporações passaram a revisar suas imagens publicitárias, entre elas a Mattel, que em 1967 lançou Francie, a primeir a amiga negra da Barbie (SCHWARZ, 2006).

Em 1980, a primeira Barbie negra foi lançada, apresentando cabelos crespos, em estilo afro. Nesta década, novas bonecas negras e hispânicas foram introduzidas no mercado pela Mattel, pois as populações negra, hispân ica e outros grupos étnicos aumentavam nos Estados Unidos. O grande potencial de vendas das bonecas étnicas fez com que a empresa lançasse também Teresa, a amiga latino-americana da Barbie, e Kira, a amiga asiática (SCHWARZ, 2006).

Em 1991, a Mattel legitimou esse mercado lançando três bonecas negras de tons diferentes de pele, o que acarretou no aumento das vendas e na abertura de um caminho promissor para as bonecas afro-americanas produzidas há mais tempo pelas outras empresas. As três bonecas da Mattel, Shani, Asha e Nichelle, eram descritas pela fabricante "esculpidas realisticamente dos pés a cabeça para refletir a beleza natural da mulher afro -americana" (ROGERS, 1999, ROVERI, 2008). Porém, não foi criado um novo padrão de corpo para essas bonecas, os corpos da "Barbie-padrão" foram meramente pintados de negro. Segundo Roveri (2009), as descrições da fabricante sobre Shani mostram que a boneca é jovem, bonita e vivaz, sabe o que ela quer e tem autoconfiança para ir atrás de seus ideais; Shani não é ap enas um belo rosto, ela é luz e escuridão.

O'Sickey (2002, p. 44) descreve que a Mattel comemorou o lançamento das bonecas negras produzidas após 21 anos da "Barbie-padrão" na revista Barbie Magazine de 1990, afirmando que "agora, todas as meninas podem ve r a si próprias pelos olhos da Barbie".

A "Barbie diversidade" não conhece obstáculos, ela troca de pele como troca de roupa. Mudar as cores do plástico da boneca não significa produzir uma imagem positiva de diversas etnias. Todos os emblemas de Barbie que ilustram sites, livros, filmes são feitos a partir da imagem branca, loira e de olhos azuis, como se a Mattel procurasse deixar claro que a Barbie real é a loira e "não étnica" e as demais bonecas, cada uma com seu nome, não são "Barbie", mas as amigas dela. (ROVERI, 2008, p.) 
A Mattel passou a explorar mais o marketing multicultural através da linha Bonecas do Mundo (figura 3). Nesta série de bonecas Barbie, a publicidade voltou -se não apenas para as meninas, como também para os adultos colecionadores, representando diferentes culturas através de supostos trajes típicos. Por exemplo, a Barbie Brasileira (figura 4) era morena, representada em roupas de carnaval. O texto que a descreve diz que "a boneca Barbie brasileira está vestida para um desfile fabuloso. Sua roupa festiva inclui uma saia rosa rodada em camadas, top e um cocar colorido rosa. Ela está pronta para a dança, diversão e comemoração!” (MATTEL, 2010a). Em 2005, a boneca foi relançada através da coleção Festivais do Mundo (figura 5), descrita da seguinte forma:

Todos os anos, a cidade do Rio de Janeiro entra em erupção em um frenesi de música, dança, lantejoulas e penas, enquanto os cariocas (habitantes locais) e inúmeros visitantes comemoram o carnaval! Em homenagem a alegria do Rio de Janeiro, a celebração de uma semana, uma boneca Barbie usa um traje incrível brasileiro com uma fantasia roxa brilhante, com um marcante top e uma sai a curta. Sapatos plataforma dourados e um cocar fabuloso completam o conjunto quen tequente-quente. (MATTEL, 2010a).

As diferenças culturais descritas pela Mattel através da coleção Bonecas do Mundo (figura 3) reforçam estereótipos étnicos, principalmente através das roupas e acessórios, supostamente usados pelas mulheres de diferentes nacionalidades. No caso da boneca brasileira, a exposição do corpo, as vestes de carnaval, o tom de pele moreno e os cabelos cacheados remetendo às características da mulher mulata brasileira, além da menção à alegria do carnaval do Rio de Janeiro são características que marcam as duas versões da boneca.

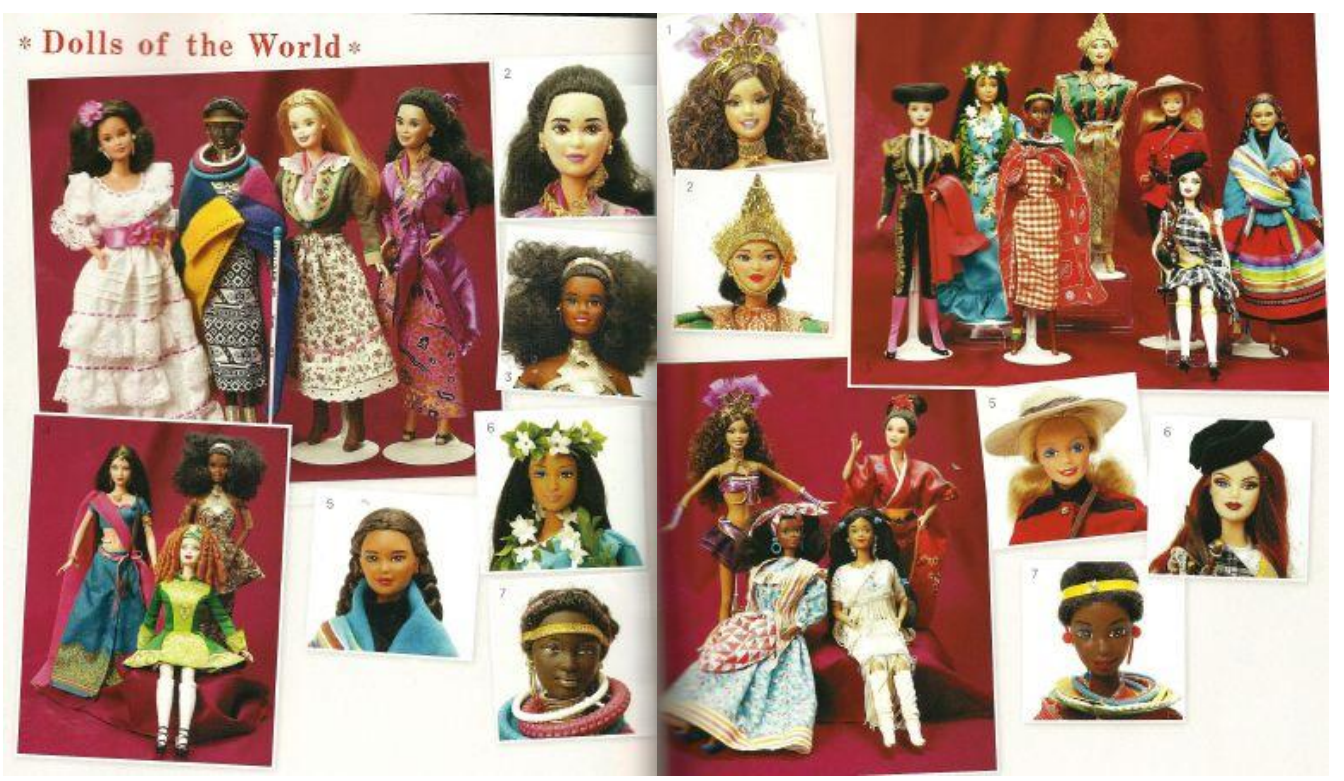

Figura 3: Barbies do Mundo (STONE, 2010) 


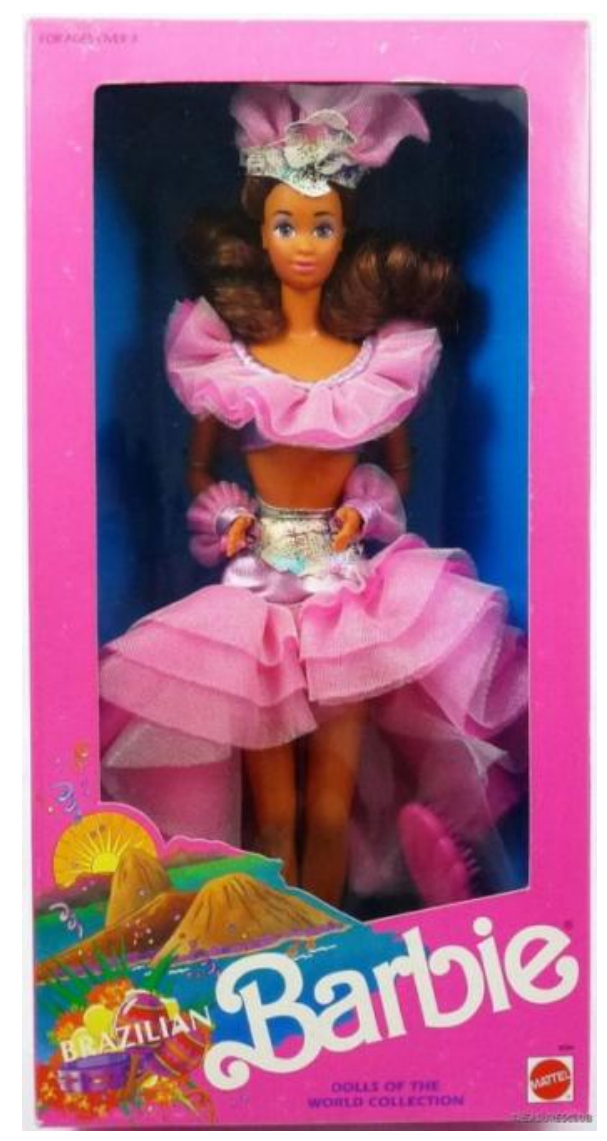

Figura 4: Brazilian Barbie (AUGUSTYNIAK, 2009)

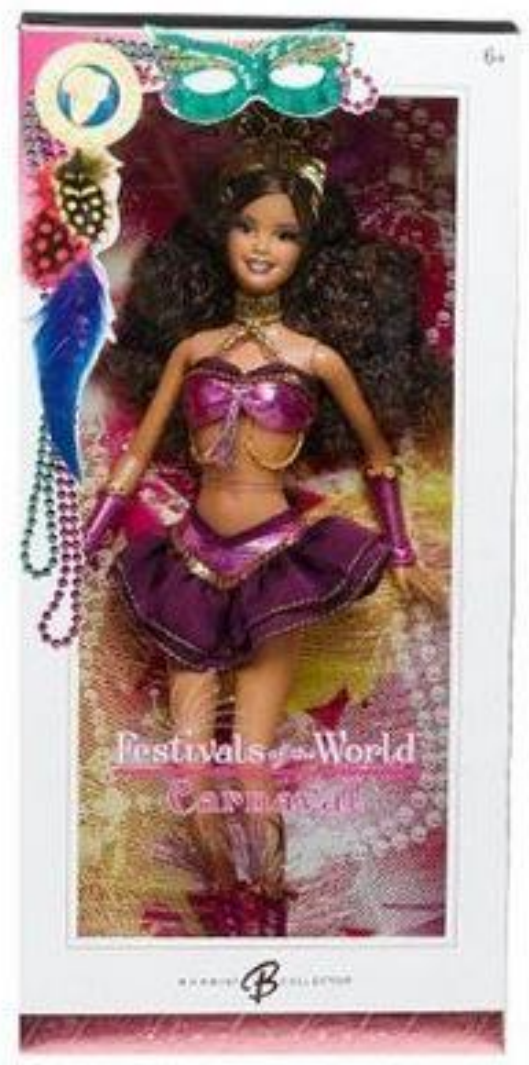

Figura 5: Barbie Festivals of the World - Carnaval (AUGUSTYNIAK, 2009)

Apesar da pretensa plasticidade democrática de representar a diversidade cultural e étnica, a Mattel perpetua os padrões hegemônicos de beleza, pois, qualquer que seja a etnia representada, Barbie sempre estará magra, na ponta dos pés, com seios grandes. Barbie nunca foi representada obesa, idosa, grávida, portadora de necessidades especiais. Essas diferenças são relegadas às "outras" bonecas do "Universo Barbie". Um exemplo é o casal idoso, pais da boneca Midge, amiga grávida da Barbie. Apesar dos cabelos brancos, das rugas e das roupas, esses bonecos apresentam corpos com o mesmo padrão de beleza difundido pela Barbie (DORNELLES, 2003, 2010).

Em nenhuma das coleções da cultura mundial Barbie foi representada como mulçumana. Em 2003, a companhia Síria Newboy Design Stud io introduziu uma nova, controversa e popular boneca. Ela tinha a aparência e estilo muito parecidos com os da Barbie, cabelos e olhos castanhos, usa lenço preto na cabeça e roupas tradicionais da religião 
muçulmana, seu nome era Fulla. Terrenée (2008) explica que Fulla é uma versão mais modesta da Barbie, ela representa uma mulher criada nos costume s muçulmanos, que respeita as tradições, é caridosa e ama seus amigos e familiares. Ela possui profissões respeitáveis, como professora e médica, e frequenteme nte é representada rezando, cozinhando e lendo. Assim como a Barbie, Fulla apresenta o comportamento e costumes de uma cultura dominante.

Becky, a amiga tetraplégica da Barbie, lançada em 1996, era uma estudante de fotografia, participou das paraolimpíadas do ano 2000; porém, com sua cadeira cor-de-rosa, Becky não cabia no carro da Barbie, no avião da Barbie e não podia subir para os andares superiores da "Casa dos Sonhos da Barbie", pois esta não tinha acessibilidade (LORD, 2004). Becky não estava incluída na rica vida de sua amiga.

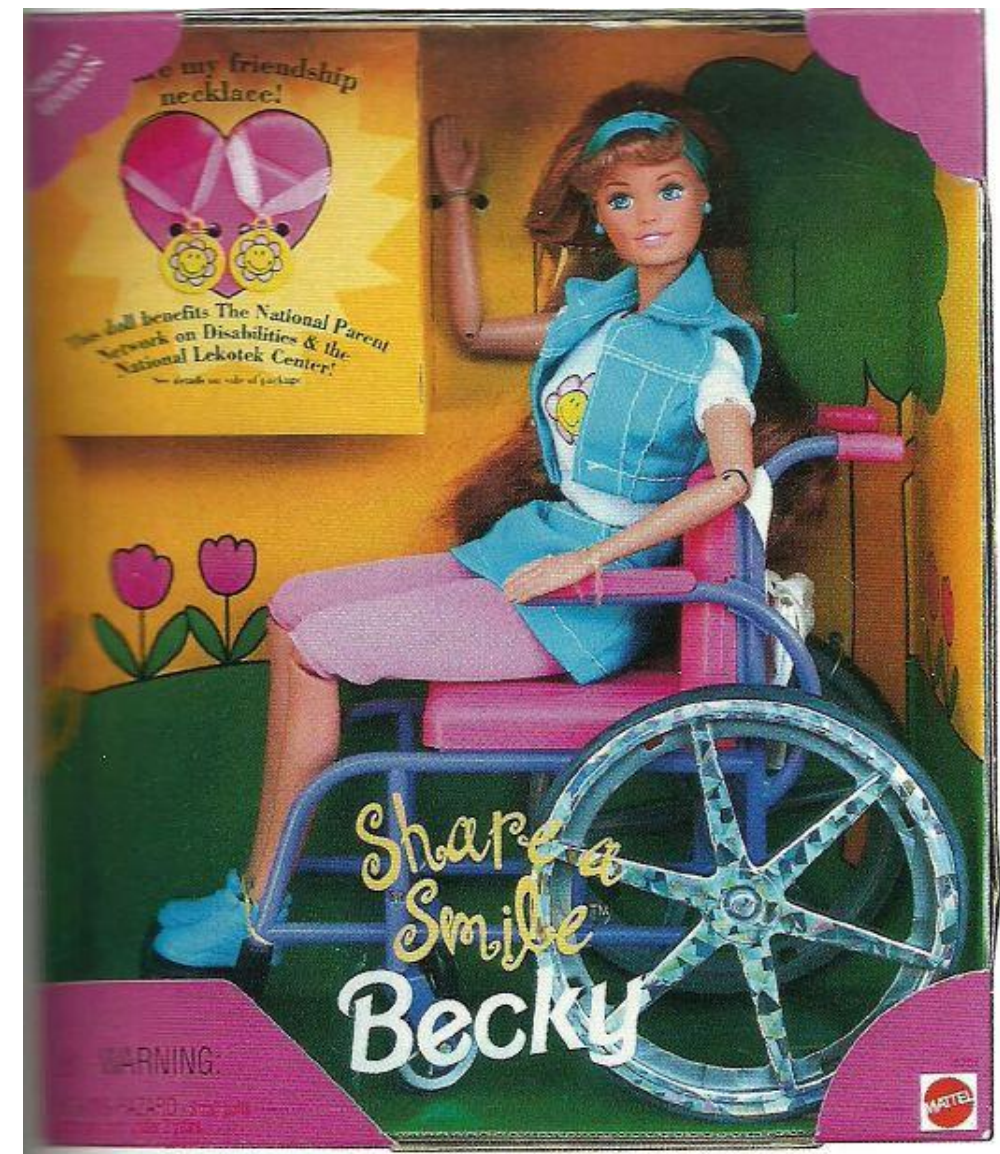

Figura 6: Becky, amiga cadeirante da Barbie (AUGUSTYNIAK, 2009)

A primeira coleção de bonecas exclusivamente negras lançadas pela Matt el, a Barbie So in Style, foi lançada em 2009. A designer Stacey McBride-Irby tinha como objetivo produzir bonecas mais fiéis aos tipos físicos e culturais da comunidade negra americana; 
porém, observa-se que as roupas, os acessórios, a fisionomia e os costumes das duas bonecas são os mesmos, diferindo apenas na cor do plástico do qu al são fabricadas (Mattel, 2010c). Dessa forma, as bonecas negras não significam a democratização dos brinquedos ou uma problematização da diversidade, mas uma ampliação do mercado de bonecas, que procura atingir um número maior de meninas consumidoras. Como afirma $S$ teinberg (2001, p.333),

\begin{abstract}
O que está acontecendo aqui? A Mattel definiu etnia como diferente do branco. A Barbie normal, loira, é o padrão a partir do qual as "outras" surgem. Como emula a cultura dominante, a norma é a Barbie; sem um título, todas as outra s Barbies são qualificadas por sua linguagem, alimentos e danças 'nativas'. Tentando ser multiculturais, pais compram essas bonecas para suas filhas para e nsiná-las sobre "outros" povos [...] Barbie dividiu as bonecas dentro das culturas dominantes e marginais. A brancura da Barbie a privilegia a não ser questionada; ela é o padrão para todas as outras.
\end{abstract}

O sucesso da boneca Barbie e sua permanência no mercado se devem também pela representação de diferentes raças e etnias. As amigas da Barbie mostram que a emergência de bonecas negras não advém de uma preocupação em respeitar a diversidade, mas da expansão das vendas proporcionadas por essas novas bonecas. Reforçam a supremacia das características hegemônicas, uma vez que seus corpos plásticos são apenas pin tados de negro. As representações das características fenotípicas permanecem as mesmas: os longos cabelos lisos, o nariz fino, os lábios e a cor d os olhos (SCHWARZ, 2006; TERRENÈE, 2008). A boneca loira continua sendo o padrão de beleza na qual as outras s ão fabricadas.

$\mathrm{Na}$ produção das bonecas, algumas características se sobrepõem a outras, produzindo ideias do que seja o normal e o patológico. Todas aquelas que não apresentam essas características são consideradas diferentes e, com oferta bastante reduzida, são difíceis de serem encontradas, são "menos normais”. Conforme afirma LOURO (1997, p. 49-50): "Em nossa sociedade, devido à hegemonia branca, masculina, heterossexual, cristã, têm sido nomeados e nomeadas como diferentes aqueles e aquelas que não compa rtilham desses atributos."

Ao eleger uma estética corporal, uma raça, um gênero ou geração como "a melhor" se naturaliza e generaliza apenas um modo de subjetivação, e tudo o que é diferente se torna negativo. Isso ocorre também com a produção de bonecos e bonecas, que não devem estar fora da norma vigente. Para Dornelles (2003):

\footnotetext{
Algumas materialidades se sobrepõem a outras, produzindo certas 'normalidades', desse modo, é 'natural', no caso do uso de bonecos e bonecas, que os mesmos ao fazerem parte da sala de aula de crianças pequenas sejam da raça branca, com olhos azuis e longos cabelos loiros. Assim, tudo o que escapa ou se apresenta diferente
} 
deste 'modelo de normalidade', desta 'verdade' acerca da raça branca, é o 'diferente', o 'outro'. E este é o tipo de brinquedo consumido em série para crianças no que tange às 'diferenças' sejam elas raciais, de gênero, geração ou etnia. (DORNELLES, 2003, p.4).

As bonecas são objetos de identificação e representação da normalidade, retrat o de uma determinada época e lugar através de marcas sociais que estão imersas em relações de poder. Tais marcas revestem-se de ricos significados culturais do ideal de beleza, de corpo e de sujeito. Ao elencar determinadas características como "as melhores", os corpos dos bonecos e bonecas fabricam modos de subjetivação que produzem "verdades" sobre como deve ser o corpo, o comportamento e as atitudes normais.

As subjetividades são formadas em um processo contínuo, fluído e inventado no transcurso de complexas histórias e vivências imbuídas de sentimentos de pertença, constituídos no interior de jogos de poder. As múltiplas subjetividades apresentadas pelos artefatos culturais, entre eles os brinquedos, produzem efeitos na constituição dos infantis (DORNELLES, 2003).

As bonecas podem parecer, a princípio, objetos inocentes destinados às crianças. Contudo, estão imersas nas relações de poder, apresentando discursos implícitos à sua materialidade do que é bom, agradável, normal e verdadeiro para a cultura hegemônica. As bonecas apresentam muito dessa cultura e do padrão de beleza eurocêntrico: pele branca e olhos claros, corpo magro e cabelo claro e liso, o que ensina a supremacia de um corpo, raça e modo de ser.

\section{O que mais se aprende com a Barbie?}

As bonecas têm passado por grandes transformações ao longo da história. $\mathrm{Na}$ antiguidade, elas tinham estreita relação com a cerimônia religiosa e comunitária. Ess a relação foi se desfazendo e as boneca s foram perdendo seu caráter comunitário para se tornar um artefato voltado exclusivamente ao universo infantil, durante a época marcada pela emergência do sentimento de infância no ocidente, que foi seguida por diversos estudos que valorizaram o brinquedo e o brincar, principalmente no campo da pedagogia e do desenvolvimento da psicanálise infa ntil.

Barbie foi comparada por Lord (2004, p.75) com amuletos matriarcais de fertilidade feitos na pré-história, representados com corpos femininos, que ficavam em pé se fincad os no chão, evocando uma ligação com a Terra. A Barbie também não pode ficar em pé, devido aos seus pés arqueados. Somente um suporte de acrílico ou a mão da menina sustentam -na. 
Muitas dessas figuras religiosas são objetos de tradição usados até o presente para ensinar às crianças da Índia os pilares de sua fé religiosa.

A Barbie também cumpre um papel educativo na cultura ocidental. Envolta em um mundo de beleza, riqueza e aventura, que supostamente valoriza a diversidade e as diferenças, a Barbie está imersa em uma pedagogia cultural, com o intuito de ensinar a supremacia de um tipo de corpo, raça e comportamento, além da produção de subjetividades infantis. A pedagogia analisada da boneca mostra que a pressão da publicidade impressa e difundida através de diferentes artefatos incorpora valores e modelos que são ubíquos na sociedade atual. O marketing por trás das Barbies étnicas, que pretendem representar minorias da sociedade, reforça as representações estereotipadas e a exclusão de determinados grupos. A Barbie personifica a fantasia de um mundo glamoroso, um ideal de beleza feminino, branco, magro e loiro.

\section{Referências}

ARIÈS, P. História Social da Criança e da Família. Rio de Janeiro: LTC, 2006.

AugustyniaK, M. Barbie Doll Photo Álbum: 1959 to 2009 identification e values. Collector Books, 2010.

BARTHES, Roland. Mitologias. São Paulo: Difel, 1982.

BROUGÈRE, G. Brinquedo e Cultura. São Paulo: Cortez, 2001.

. Brinquedos e Companhia. São Paulo: Cortez, 2004.

BUJES, M. I. Infâncias e Maquinarias. Rio de Janeiro: DP\&A, 2002.

Criança e Brinquedo: feitos um para o outr o? In: COSTA, M. V. VEIGA-NETO, Alfredo [et al.]. Estudos Culturais em Educação: mídia, arquitetura, brinquedo, biologia, literatura, cinema... Porto Alegre: Editora da UFRGS, 2004.

CONNEL, R. W. Masculinities. California II, 2005.

DEBOUZY, M. La poupée Barbie. Clio, número 4-1996, Le temps des jeunes filles, [online]. Disponível em : http://clio.revues.org/index446.html. Acesso : 10/02/2011.

DORNELLES, L. V. Infâncias que nos escapam: da criança na rua à criança cyber. Petrópolis: Vozes, 2008.

Na escola infantil todo mundo brinca se você brinca. In: KAERCHER, G. E. CRAIDY (org.) Educação Infantil: pra que te quero? Porto alegre: Artmed, 2001. 
O brinquedo e a Produção do Sujeito Infan til. Centro de Documentação e

Informação sobre a Criança. Universidade do Minho. Instituto de Estudos da Criança. 2003.

Disponível em: 〈http://cedic.iec.uminho.pt/Textos_de_Trabalho/textos/obrinquedo.pdf >

Acesso em: 03 de dez. de 2010.

FOUCAULT, M. Microfísica do Poder. Rio de Janeiro: Edições Graal, 1979.

GIROUX, H. A. Praticando Estudos Culturais nas Faculdades de Educação. In: SILVA, T. T. Alienígenas na Sala de Aula: Uma Introdução aos estudos culturais em educação. Petrópolis: Vozes, 2009.

LORD, M. G. Forever Barbie - The unauthorized biography of a real doll. New York:

Walker \& Company, 2004.

LOURO, Guacira L. Um corpo estranho: ensaios sobre sexualidade e teoria queer. Belo Horizonte: Autentica, 2004.

MITCHELL, C. A. REID-WALSH, J. Girl Culture: An Encyclopedia. Greenwood Publishing Group, 2007

O'SICKEY, Ingeborg Majer. A Revista Barbie e a utilização estética do corpo das meninas. In:BENSTOCK, S.; FERRIS, S. (orgs .). Por dentro da moda. Rio de Janeiro: Rocco, 2002.

ROVERI, F. T. Barbie - Tudo o que você quer ser... ou considerações sobre a educação de meninas. Dissertação de Mestrado. Universidade Estadual de Campinas, Faculdade de Educação, 2008.

ROGERS, Mary F. Barbie culture. London: Sage Publications, 1999.

SANTOMÉ, J. T. Culturas Negadas e Silenciadas no Currículo. In: SILVA, T. T. Alienígenas na Sala de Aula: Uma Introdução aos estudos culturais em educação. Petrópolis: Vozes, 2009.

SCHWARZ, M. T. Native American Barbie: The Marketing of Euro-American Desires. American Studies, 46:3/4 (Fall-Winter 2005): 295-326. Disponível em: https://journals.ku.edu/index.php/amerstud/articl e/view/2964/2923. Acesso: 20/07/2011.

SOUZA, F. M. Revirando Malas: entre histórias de bonecas e crianças. Dissertação (Mestrado em Educação) - Programa de Pós-Graduação em Educação, Faculdade de Educação, Universidade Federal do Rio Grande do Sul, Port o Alegre, 2009.

STONE, T. L. The Good, The Bad and The Barbie : a doll's history and her impact on US. New York: Viking, 2010.

STEINBERG, S. R. A mimada que tem tudo. In: STEINBERG, S. R. KINCHELOE, J. L. Cultura Infantil: a construção corporativa da infân cia. Rio de Janeiro: Civilização Brasileira, 2004.

STEINBERG, S. R. [et al]. Boy Culture: an encyclopedia. California: Greenwood Publishing Group, 2010. 
TERRENÉE, R. Fulla, the veiled Barbie: An analysis of cultural imperialism and agency. MAI Review, 2008, 2, Santa Cruz Report. Disponível em:

http://review.mai.ac.nz/index.php/MR/article/viewFile/132/151. Acesso: 16/07/2011.

ZEGAI, M. Les jouets pour enfants au regard du genre. (Memoire de Master) - Departement de Sociologie, UFR Des Sciences Sociales et des Humsnites, Universite de Versailles -SaintQuentin, Versailles, 2007.

\section{SITES PESQUISADOS}

MATTEL. Barbie escola de Princesas. 2011a. Disponível em:

http://www.escoladeprincesas.com.br/?utm_source=BarbieComBr\%26utm_medium=Sky\%26 utm_campaign=PreLancamento . Acesso: 17/09/2011.

MATTEL. Brazilian Barbie Doll. 2010b. Disponível em:

http://www.barbiecollector.com/shop/doll/brazilian -barbie-doll-09094 . Acesso: 04/05/2011.

MATTEL. Carnaval Barbie Doll. 2010c. Disponível em:

http://www.barbiecollector.com/shop/doll/carnaval -barbie-doll\#page-20 . Acesso:

04/05/2011.

MATTEL. Fashion Fever. 2011c. Disponível em: http://br.barbie.com/activities/fashion/ .

Acesso: 10/09/2011.

MATTEL. Max Steel. 2011b. Disponível em: http://br.maxsteel.com/br/. Acesso:

23/07/2011.

MATTEL. Meet the S. I. S. Friends! 2010d. Disponível em:

http://www.barbie.com/activities/friends/soinstyle/\#/characters/ . Acesso: 07/05/2011.

MATTEL. Segredos de Estilo. 2010a. Disponível em:

http://br.barbie.com/fashionistas/\#/StyleSecrets/ . Acesso: 10/05/2011.

MATTEL. Viva o Rosa - Celebre o aniversário da Barbie. 2009. Disponível em:

http://www.barbievivaorosa.com.br/. Acesso: 30/04/2011.

Filmes Pesquisados

MATTEL ENTERTAINMENT, MAINFRAME ENTERTRAINMENT. Barbie A Princesa e a Plebeia. DVD. 2004.

MATTEL ENTERTAINMENT, MAINFRAME ENTERTRAINMENT. Barbie em A Escola de Princesas. DVD. 2011. 